\title{
Uptake of Sulphates in Mucopolysaccharides Esterified with Sulphuric Acid in the Skin of Adult Rats after Intraperitoneal Injection of $\mathbf{S}^{35}$-labelled Sodium Sulphate
}

\author{
HARRY BOSTRÖM and SVEN GARDELL \\ Chemistry Department II, Karolinska Institutet, Stockholm, Sweden
}

M eyer and Chaffee ${ }^{1}$ reported the occurrence of chondroitin sulphate in the skin of swine, and Pearch and Watson ${ }^{2}$ showed it to be present in human skin.

Dziewiatkowski et $a l .^{3}$ found that articular cartilage of 7 days old rats showed a high uptake of $\mathbf{S}^{35}$ after injection of labelled sodium sulphate. The major portion of the labelled sulphur in cartilage is present in the sulphate group of the chondroitin sulphate (Dziewiatkowski 4 , Boström ${ }^{5}$ ) from which it is slowly eliminated (Boström ${ }^{5}$ ).

In the present investigation the exchange of the ester sulphate group in the chondroitin sulphate of the skin has been studied. A mucopolysaccharide fraction containing sulphate esters was isolated from the skin of adult rats at different times during a period of 16 days after intraperitoneal injection of sodium sulphate labelled with $\mathbf{S}^{35}$.

\section{EXPERIMENTAL}

Nine groups of adult white rats *, each group containing 20 animals weighing 250 to $300 \mathrm{~g}$, were given sodium sulphate ** labelled with $\mathrm{S}^{35}$ intraperitoneally, $1.5 \mathrm{mg}$ of sodium sulphate dissolved in $0.5 \mathrm{ml}$ of water to each animal $\left(3.5 \times 10^{6}\right.$ counts per minute per square centimetre measured as barium sulphate at infinite thickness). The animals were killed at intervals, those in the first group after two hours, those in the last group after 16 days, and the animals within the different groups were pooled. The skin was removed and washed thoroughly with cold water, then finely ground in a mechanical meat grinder.

* The same animals as used for previous experiments (Boström ${ }^{5}$ ).

** Obtained from A. E. R. E., Harwell, England.

Acta Chem. Scand. 7 (1953) No. 1 
The material was immediately suspended in 20 parts of acetone, filtered with suction and dried with acetone. The dry powder from each group of 20 animals weighed 200 to $250 \mathrm{~g}$ and was divided into three portions which were treated as follows.

I. Twenty $\mathrm{g}$ of the dry powder was hydrolyzed with $100 \mathrm{ml}$ of $6 \mathrm{~N} \mathrm{HCl}$ on a boiling water bath for four hours. The hydrolysate was diluted to $600 \mathrm{ml}$ and the sulphate was precipitated with barium chloride. The precipitate was collected on a Gooch porcelain crucible, ignited and weighed. The combined free and ester sulphates in the skin corresponded to 0.02 to 0.03 per cent of sulphur in the dry powder.

II. Five $\mathrm{g}$ of dry powder was hydrolyzed with $20 \mathrm{ml}$ of 10 per cent sodium hydroxide on a boiling water bath overnight. The solution was transferred to a nickel crucible and evaporated to approximately $5 \mathrm{ml}$. Five $\mathrm{g}$ of anhydrous sodium carbonate was added and the solution was evaporated in an oven at $110-120^{\circ} \mathrm{C}$ overnight. The material was then oxidized with sodium peroxide, as recommended by Bailey ${ }^{6}$, and the sulphate was precipitated as barium sulphate. The total sulphur content of the dry powder was found to be approximately 0.5 per cent.

III. The remainder of the dry powder, about 175 to $225 \mathrm{~g}$, was added in small portions to 11 . of boiling water. When addition was completed, the suspension was boiled for 15 minutes, then allowed to cool to about $40^{\circ} \mathrm{C}$, and the $\mathrm{pH}$ was adjusted to $7.5-8$ with $2 \mathrm{~N}$ sodium hydroxide. Five $\mathrm{ml}$ of glycerol extract of pancreas dry powder was added and the mass was digested in the presence of toluene at $40^{\circ} \mathrm{C}$. The $\mathrm{pH}$ of the mass, which during the digestion turned slightly acid was tested at frequent intervals and when necessary adjusted to 7.5-8. The digestion was followed by determining the amount of amino nitrogen liberated.

The glycerol extract had been obtained by shaking 1 part of pancreas dry powder for four hours with 10 parts of 87 per cent glycerol; the mixture was then diluted with an equal volume of water and filtered.

Five $\mathrm{ml}$ portions of glycerol extract were added during the course of the digestion after one, two and three weeks, respectively. As after this period of time the digestion did not seem to proceed further, it was interrupted and the mixture was concentrated to a thick syrup and dialyzed against running water in a cellophane bag for $\mathbf{4 8}$ hours. After further concentration, 10 volumes of alcohol were added and the precipitate was centrifuged and dried with alcohol and ether. It was again dissolved in about $250 \mathrm{ml}$ of water and digested with $5 \mathrm{ml}$ of a glycerol extract of pig's intestinal mucosa obtained in the following way: 1 part of the intestinal mucosa was shaken for four hours with 10 parts of 87 per cent glycerol, diluted with 2 volumes of water and centrifuged. After digestion for about two weeks the mixture was concentrated by evaporation, dialyzed, concentrated again, and treated with 10 volumes of alcohol. The precipitate was suspended in $100 \mathrm{ml}$ of water, made alkaline to litmus with $2 \mathrm{~N}$ sodium hydroxide and centrifuged. The clear centrifugate was precipitated with 10 volumes of alcohol and the precipitate formed was dissolved in a very small volume of water, and the solution centrifuged after acidification to Congo red with $2 \mathrm{~N} \mathrm{HCl}$. The centrifugate was precipitated with 10 volumes of alcohol. The precipitate formed was again dissolved in water, $5 \mathrm{gm}$ of thoroughly washed Lloyd's reagent was added and the mixture made just acid to Congo red with HCl. The sample was shaken for 15 minutes and centrifuged, and the clear centrifugate was precipitated with 10 volumes of alcohol. The precipitate was dried with alcohol and ether. Yield, 250 to $800 \mathrm{mg}$.

Acta Chem. Scand. 7 (1953) No. 1 
The analyses of the various preparations are given in Table 1.

Table 1. Analysis of the mucopolysaccharide fractions.

\begin{tabular}{|c|c|c|c|}
\hline & \multicolumn{3}{|c|}{ Per cent of air dry substance } \\
\cline { 2 - 4 } & Mean value & Maximum & Minimum \\
\hline $\begin{array}{c}\text { Nitrogen } \\
\text { (Kjeldahl) } \\
\text { Sulphur in ester } \\
\text { sulphates } \\
\text { Uronic acid } \\
\text { (Tracy 11) }\end{array}$ & 4.76 & 6.73 & 3.42 \\
\hline
\end{tabular}

\section{CHARACTERIZATION OF THE SKIN MUCOPOLYSACCHARIDE}

In order to characterize the polysaccharide more precisely, the following experiment was carried out. When the amount of material necessary for the analyses and radioactivity measurements had been taken, the nine preparations were combined. The polysaccharide was then subjected to electrophoresis in Hyflo Supercel as described by Gardell, Gordon and Åqvist ?. The result of this investigation is shown in Fig. 1.

Two distinct components were present. Three runs were made and all the fractions containing the same component were combined. After evaporation of the solution in vacuo to a syrup the polysaccharide was precipitated with alcohol, dried and weighed. The substances were then hydrolyzed on a boiling water bath for 8 hours with $6 N$ hydrochloric acid. As the amount of substance was too small to permit measurement of radioactivity and determination of sulphur, sodium sulphate equivalent to $25 \mathrm{mg}$ of barium sulphate was added to the hydrolysate and the sulphate was precipitated with a slight excess of barium chloride. The precipitate was collected for radioactivity measurements in the usual way and weighed. This gives the approximate amount of sulphur present in the polysaccharide. The supernatant was evaporated several times in vacuo to remove the hydrochloric acid and finally taken up in $2 \mathrm{ml}$ of $0.3 \mathrm{~N}$ hydrochloric acid. The amino sugar in the hydrolysate was then determined qualitatively and quantitatively by the chromatographic method described by Gardell ${ }^{8}$. Since the polysaccharide was a mixture of the original nine preparations, no quantitative interpretation of the radioactivity measurement was made on this preparation. The slow component, 
Fig. 1. Electrophoresis of rat skin polysaccharide in Hyflo Supercel.

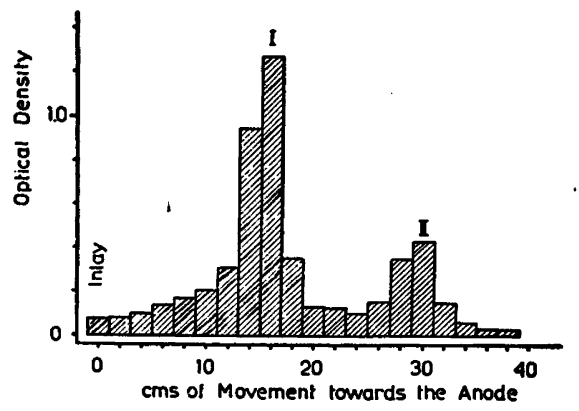

however, showed no significant radioactivity while the fast one had about 1000 counts $/ \mathrm{min} . / \mathrm{cm}^{2}$. The results of the chemical analyses are given in Table 2.

Table 2. Analysis of the slow (I) and fast (II) moving fractions of the skin polysaccharide.

\begin{tabular}{|c|c|c|c|c|}
\hline \multirow{2}{*}{ Component } & \multirow{2}{*}{ Weight } & \multicolumn{3}{|c|}{ Per cent of air dry substance } \\
\cline { 3 - 5 } & $\begin{array}{c}\text { Sulphur in } \\
\text { ester sulphates }\end{array}$ & Glucosamine-HCl & Galactosamine-HCl \\
\hline I & $31.6 \mathrm{mg}$ & None & 10.4 & Trace \\
II & $15.2 \mathrm{mg}$ & 4 & Trace & 19.8 \\
\hline
\end{tabular}

The analysis of the polysaccharide from the rat skin thus indicated that the sulphur-containing portion was chondroitin sulphate. This is in agreement with the results obtained by Meyer and Chaffee ${ }^{1}$ who found chondroitin sulphate and "isomers" of it as the only sulphur-containing polysaccharides in the skin of pig. The slow moving fraction contains hyaluronic acid.

\section{RADIOACTIVITY MEASUREMENTS}

In order to exclude the possibility that the samples of mucopolysaccharides obtained were contaminated with free sulphates labelled with $S^{35}$ the following experiment was undertaken.

$100 \mathrm{mg}$ of one of the samples was dissolved in $20 \mathrm{ml}$ of distilled water, $200 \mathrm{mg}$ of non-labelled sodium sulphate was added and the solution was dialyzed against running tap-water in a cellophane bag for 24 hours. After Acta Chem. Scand. 7 (1953) No. 1 


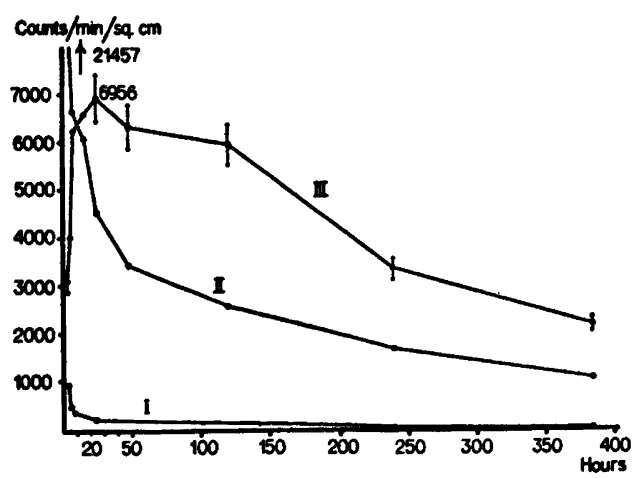

Fig. 2. Raidioactivity (as counts/min. $/ \mathrm{cm}^{2}$ ) plotted against time in hours. Curve I relates to the total sulphur of the skin, curve II sulphur obtained after acid hydrolysis of the skin, and curve III ester-bound sulphate in the isolated mucopolysaccharide fraction of the skin. The possible errors in the measurements are marked on curve III.

concentration by evaporation the sample was precipitated with 4 volumes of alcohol and dried with alcohol and ether.

No significant difference in the radioactivity of the sample before and after this procedure could be demonstrated.

Approximately $250 \mathrm{mg}$ of these mucopolysaccharide preparations were hydrolyzed with $20 \mathrm{ml}$ of $6 \mathrm{~N} \mathrm{HCl}$, and the sulphate was precipitated as barium sulphate for radioactivity measurements.

The radioactivity of the various barium sulphate precipitates was determined as described in a previous communication (Boström ${ }^{5}$ ), using a GeigerMüller counter with $2.1 \mathrm{mg}$ per square centimetre mica end window tubes. After plating, the samples contained at least $25 \mathrm{mg}$ of barium sulphate per square centimetre, corresponding roughly to infinite thickness. The results are expressed as counts per minute per square centimetre. The error in measuring the radioactivity of a sample amounted to \pm 7 per cent.

\section{RESULTS AND DISCUSSION}

Fig. 2 shows the measured activities, expressed as counts per minute per square centimetre, plotted against the time in hours. The total sulphur in the skin of rats (curve I) shows marked activity merely during the first few hours (950 counts/min. after two hours), followed by a rapid decline (200 counts/min. after 24 hours and 20 counts/min. after 16 days). Evidently the administered sulphate labelled with $\mathrm{S}^{35}$ was highly diluted with sulphurcontaining compounds with an extremely low or no demonstrable uptake of sulphur after injection of the labelled sulphate. According to Tarver and Smith ${ }^{9}$ sulphate sulphur cannot be utilized for the synthesis of, for example, cystine in the rat. 
Fig. 3. Radioactivity (as counts/min./ $/ \mathrm{cm}^{2}$ ) plotted against time in hours. Curve I relates to the total sulphur in the blood, curve II free sulphates in the costal muscles, and curve III the chondroitin sulphate. The possible errors in measurements are marked on curve III.

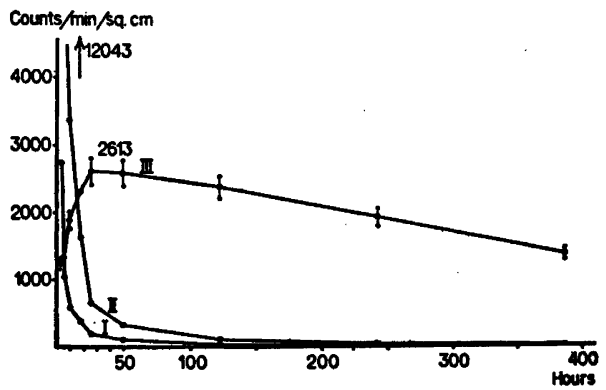

Curve II, which was obtained after acid hydrolysis of the dry powder prepared from rat's skin, shows a very high initial value $(21500$ counts/min. after two hours), followed by a very rapid decline (3 500 counts/min. after 48 hours), and a considerably slower fall during the remaining part of the experimental period ( 1020 counts/min. after 16 days). This curve is a summation of the curves for the free sulphates and the ester sulphates. The initial rapid decline in activity is due to the quick excretion of free sulphates (Dziewiatkowski ${ }^{10}$, Boström ${ }^{5}$ ), while the more gently sloping portion of the curve depends mainly on radioactive sulphur in the ester sulphates.

Curve III shows the radioactivity of the sulphates liberated during acid hydrolysis of the skin mucopolysaccharide. This graph shows a 2 hour value of 3400 counts $/ \mathrm{min}$. and a steep rise to a maximum value of 6950 counts $/ \mathrm{min}$. after 24 hours, followed by a relatively slow decline to 1020 counts $/ \mathrm{min}$. after 16 days. Nine to ten days after injection the content of isotope is half of the maximum.

If this graph is compared with the corresponding graph for chondroitin sulphate isolated from costal cartilage of rats in previous work (Boström ${ }^{5}$, see Fig. 3), it is found that the curve for the mucopolysaccharides in the rat's skin reaches a considerably higher level and also shows a more rapid decline. Half of the radioactive sulphur which was introduced into the chondroitin sulphate of the costal cartilage was eliminated in about 17 days. The higher level reached in the skin polysaccharides is probably due to a more rapid exchange of fluid in the skin than in the cartilage. Both curves show a maximum uptake about 24 hours after injection.

\section{SUMMARY}

The exchange of the sulphate group in the mucopolysaccharides of the skin of the rat was studied by following the uptake and disappearance of $\mathrm{S}^{35}$ during a period of 16 days after intraperitoneal injection of sodium sul- 
phate labelled with $\mathrm{S}^{35}$. Mucopolysaccharide fractions containing 1.2 to 2.0 per cent sulphur in ester sulphates were isolated from the skin of adult rats at various times after administration of $\mathrm{S}^{35}$. The sulphur-containing fraction of skin polysaccharide was identified as chondroitin sulphate. The maximum uptake of radioactive sulphur was obtained 24 hours after the injection. The decline was relatively rapid, half of the maximum value being reached after nine to ten days.

The authors are greatly indebted to Professor Erik Jorpes for his valuable advice during the course of the work.

This investigation has been aided by grants from the Swedish Medical Research Council, the Rockefeller Foundation, the Knut and Alice Wallenberg Foundation and the Vitrum Company, Stockholm.

\section{BIBLIOGRAPHY}

1. Meyer, K., and Chaffee, E. J. Biol. Chem. 138 (1941) 491.

2. Pearce, R. H., and Watson, E. M. Can. J. Research 27 (1949) 43.

3. Dziewiatkowski, D. D., Benesch, R. E., and Benesch, R. J. Biol. Chem. 178 (1949) 931.

4. Dziewiatkowski, D. D. J. Biol. Chem. 189 (1951) 187.

5. Boström, H. J. Biol. Chem. 196 (1952) 477.

6. Bailey, K. Biochem. J. 31 (1937) 1396.

7. Gardell, S., Gordon, A. H., and Åqvist, S. Acta Chem. Scand. 4 (1950) 907.

8. Gardell, S. Acta Chem. Scand. 7 (1953) 207.

9. Tarver, H., and Smith, C. L. A. J. Biol. Chem. 130 (1939) 67.

10. Dziewiatkowski, D. D. J. Biol. Chem. 178 (1949) 197.

11. Tracy, M. V. Biochem. J. 43 (1948) 185.

Received July 9, 1952. 